\title{
A CONSTRUÇÃO DE SABERES EM UM PROCESSO DE ENSINO E DE APRENDIZAGEM DE CIÊNCIAS: UMA HISTÓRIA PARA CONTAR
}

\author{
THE KNOWLEDGE OF CONSTRUCTION IN A PROCESS OF TEACHING AND LEARNING \\ SCIENCE: A TALE TO TELL
}

\section{LA CONSTRUCCIÓN DE SABERES EN UN PROCESO DE ENSEÑANZA Y APRENDIZAJE DE CIENCIAS: UNA HISTORIA QUE CONTAR}

\section{Monica Narciso Guimarães ${ }^{1}$ \\ Ana Maria Falcão de Aragão ${ }^{2}$}

\begin{abstract}
RESUMO: Nosso objetivo nesta pesquisa foi o de evidenciar os saberes adquiridos e acumulados durante o percurso no projeto Um corpo em Construção, bem como o de capturar, por meio dos registros, as interações e os significados que engendraram a construção desses saberes. A atividade pedagógica em questão é um recorte do referido projeto realizado pelos alunos do $8^{\circ}$ ano de uma instituição pública de ensino, do âmbito federal, no estado do Rio de Janeiro, que prevê a construção de um corpo humano feito no interior de um molde de acetato e de sua história como personagem em uma narrativa ficcional. Neste artigo, trazemos a narrativa pedagógica de um momento com um dos grupos quando estes alunos-autores deram vida/corpo ao personagem Carlos Eduardo. Os saberes construídos na vivência deste projeto, mediatizados pelas interações - emergentes ou intencionais - entre professora e alunos se revelam, especialmente, por um processo intencional de reflexividade. Novos olhares e novos saberes poderiam recuperar outras formas de dialogar com as múltiplas realidades que se apresentam face a face conosco nas salas de aula. Saberes que as ciências ainda não conhecem.
\end{abstract}

PALAVRAS-CHAVE: Saberes docentes. Ensino de Ciências. Narrativas pedagógicas. Reflexividade.

\begin{abstract}
Our goal in research on screen was to demonstrate the knowledge acquired and accumulated along the way in the design A Body under Construction, as well as to capture, through records, interactions and meanings that engendered the construction of this knowledge. The pedagogical activity in question is an excerpt of that project carried out by students of the 8th grade of a public educational institution, the federal level, in Rio de Janeiro, which includes the construction of a human body made within an acetate mold and its history as a character in a fictional narrative. In this article, we bring the pedagogical narrative of a time with one of the group when these students-authors gave life / body to the character Carlos Eduardo. The knowledge built on the experience of this project, mediated by interactions - emerging or intentional - between teacher and students are revealed, especially for an intentional process of reflexivity. New looks and new knowledge could retrieve other forms of dialogue with the multiple realities that come face to face with us in classrooms. Knowledge that the sciences do not yet know.
\end{abstract}

KEYWORDS: Teacher's knowledge. Science teaching. Pedagogic narratives. Reflexivity.

\footnotetext{
${ }^{1}$ Doutora em Educação pela Universidade Estadual de Campinas - UNICAMP, Campinas, SP - Brasil. Professora titular de Biologia do Colégio Dom Pedro II, município de Niterói - RJ. E-mail: monicaguimaraes@uol.com.br.

${ }^{2}$ Livre Docente e Doutora em Educação pela Universidade Estadual de Campinas, UNICAMP, Campinas, SP Brasil. Professora associada do Departamento de Psicologia Educacional da Faculdade de Educação Universidade Estadual de Campinas, UNICAMP, Campinas, SP - Brasil. E-mail: anaragao@ terra.com.br.

Recebido em: 02/07/2015 - Aprovado em: 18/12/2015.
}

\begin{tabular}{l|l|l|l|l|l|l} 
(C) ETD -Educ. Temat. Digit. & Campinas, SP & v.18 & n.1 & p. 250-268 & jan./abr.2016 & ISSN 1676-2592
\end{tabular}


RESUMEN: Nuestro objetivo en la investigación en la pantalla era para demostrar los conocimientos adquiridos y acumulados a lo largo del camino en el diseño de un proyecto llamado Cuerpo en Construcción, así como para capturar, a través de los registros, las interacciones y significados que engendraron la construcción de este conocimiento. La actividad pedagógica en cuestión es un extracto de ese proyecto llevado a cabo por los alumnos del octavo grado de una institución educativa pública, a nivel federal, en Río de Janeiro, que incluye la construcción de un cuerpo humano hecho dentro de un molde de etilo y se su historia como un personaje de un relato de ficción. En este artículo, te traemos la narración pedagógica de un tiempo con uno de los grupos cuando estos estudiantes-autores dieron vida / cuerpo al personaje de Carlos Eduardo. El conocimiento basado en la experiencia de este proyecto, mediada por interacciones - emergente o intencional - entre el profesor y los estudiantes se revela, sobre todo para un proceso intencional de la reflexividad. Nuevas miradas y nuevos conocimientos podrían recuperar otras formas de diálogo con las múltiples realidades que vienen cara a cara con nosotros en las aulas. El conocimiento de que las ciencias no saben todavía.

PALABRAS CLAVE: Saberes docentes. Enseño de Ciencias. Narrativas Pedagógicas. Reflexividad.

\section{INTRODUÇÃO}

Considerando a rede de informações na qual estamos imbricados mundialmente, o panorama internacional da evolução do ensino tem influenciado muito o quadro que vivenciamos aqui, no Brasil. Observa-se, hoje, internacionalmente, uma tendência importante para a constituição docente: a preparação para esta profissão, considerada cada vez mais complexa, pois a transmissão dos saberes escolares e sua aquisição se veem confrontados com uma nova organização da sociedade e uma nova ordem de valores. O saber que antes era tido como unificado, promotor de ascensão social, hoje, se apresenta diluído, fragmentado. É um saber que não dá conta das suas múltiplas formas de apresentação e que acaba por excluir da sua dinâmica de crescimento parcelas importantes da população.

Sadalla e Sá-Chaves (2007) lembram que refletir sobre a prática não é apenas pensar sobre ela, mas buscar na teoria os seus fundamentos. Ser um profissional reflexivo significa, nessa perspectiva, apropriar-se de teorias (neste caso, psicológicas e educacionais) que analisem o fenômeno em estudo, conscientizar-se delas e debruçar-se sobre o conjunto de sua ação, refletindo sobre seu ensino e as condições sociais nas quais está inserido.

Trocando olhares com Shulman (1986a, 1986b, 1987, 2004) e Tardif (1991, 2000, 2002, 2007, 2008), autores estudiosos de conhecimentos e saberes docentes, descobrimos que nossas concepções sobre a pessoa do educador se reúnem na ideia de que nós, educadores, carregamos a nossa história de vida - pessoal e profissional - para todo lugar a que vamos. Não há outra possibilidade. Quando entramos em sala, nela encontramos o manancial de recursos para desenvolvermos, ali, nossa proposta, nossa ação educativa. Ao sairmos dela, já não somos mais os mesmos. Nossas histórias de vida, inacabadas e em construção, tomam nova forma, agora mescladas às histórias dos sujeitos-alunos que conosco entraram em ação. E assim sucessivamente, a tarefa educativa perpassa o encontro humano. Essa concepção do educador como sujeito implicado em sua ação é tratada igualmente por Shulman e Tardif como um elemento fundamental à construção da docência e mais, aí reside o significado da mobilização e da produção dos saberes necessários ao exercício da profissão. 
Em um outro olhar, vemos que as contribuições desses autores não sugerem complementaridades com relação à tipologia dos saberes docentes, entretanto é possível observar alguns equivalentes teóricos. Seguindo orientações teórico-metodológicas diferentes, esses autores apresentam interesses investigativos que deslocam o foco para determinado tipo de saber. Enquanto Shulman se propõe a investigar o conhecimento que os professores têm dos conteúdos e a forma como representam tais conteúdos, Tardif se preocupa com a pluralidade dos saberes docentes e como se integram na dinâmica da sala de aula.

Com uma clara perspectiva cognitivista, Shulman pretende categorizar os conhecimentos utilizados pelo professor ao transpor os conteúdos disciplinares para o aprendiz. Ainda no interior dessa perspectiva, alguns anos mais tarde, Shulman amplia seu quadro interpretativo, detalhando um modelo de ação e raciocínio pedagógico. Como todo modelo, esse também não pode ser tomado como a expressão literal da realidade ou como passos rígidos a serem seguidos. Entretanto, este é um risco se pensarmos em sua utilização em uma iniciação profissional, por exemplo. Isso porque no início da docência muito provavelmente ainda não temos elementos para problematizar as etapas ou fases propostas, tornando a compreensão do modelo algo extremamente teórico e abstrato. Um risco que corremos quando modelamos uma ação ou estratégia humana é o de propor-lhe uma receita, algo que possa ser repetido para facilitar sua execução ou minimizar-lhe os erros. Um modelo de ação pedagógica não deixa de ser um modelo de ação humana e por essa razão tende a se tornar asséptico com relação às diferentes estratégias possíveis, incluindo aquelas que são imprevistas ou impensadas em um dado momento da história de vida daquele professor. Não podemos pensar, por exemplo, que serão eliminados os acasos, os recuos ou retrocessos, ou seja, fatores que interceptam a ação docente. Muitas vezes, a despeito deles, a aprendizagem ou o evento educativo ainda ocorre.

O entendimento de Shulman sobre a influência da história de vida do professor ou da 'sabedoria da prática propriamente dita' apresenta limites que devem ser superados à medida que as diversas práticas docentes forem registradas, analisadas e divulgadas amplamente. Enfocando o aspecto cognitivo da profissão, Shulman deixou de lado do seu cenário teórico um trabalho que incluísse as subjetividades dos professores, o que acreditamos torna-se uma prioridade para a formação docente. Hoje, a abordagem das histórias de vida pessoal e profissional como suporte empírico para a reflexão compreensiva da formação de si, como sujeito com uma identidade profissional construída a partir de uma multirrefencialidade, vem sustentar novos paradigmas de pesquisas, novos olhares sobre o que acontece na sala de aula.

Segundo Josso (2008), as pesquisas feitas a partir de relatos de vida permitem o acesso in vivo aos movimentos que constroem a nossa existência e apresentam uma perspectiva sustentada por uma práxis paradoxal. Esta nova práxis associaria envolvimento e distanciamento do pesquisador, sujeito de sua própria pesquisa, na construção de uma subjetividade singular - quando tomada pela objetivação de preconcepções ou pensamentos preconcebidos - e plural - quando a experiência é tomada como dispositivo de pesquisa na construção de conhecimentos. Esse paradigma do singular-plural, referido por Josso, nos dá a 
possibilidade de introduzir a humanidade em nosso ofício. Um ofício de interação, reflexão, co-construção de olhares e saberes.

O trabalho de superação proposto por Shulman, na nossa perspectiva, está, sobretudo, relacionado à superação dos limites epistemológicos dos paradigmas de pesquisa herdados do século passado. Os saberes fragmentados, as disciplinas setorizadas e recortadas que sempre fizeram parte de nossa formação acadêmica caminham junto a concepções de ciência e de pesquisa que precisam ser problematizadas a partir dos novos paradigmas e novos olhares sobre a docência como um ofício de natureza diferenciada.

A inquietação investigativa de Tardif faz dele um autor fotográfico: ele não quer perder nenhum lance! Em seus trabalhos iniciais, seu foco parece centrar-se na figura do professor, porém ao analisarmos suas pesquisas mais recentes, percebemos que seu foco se desloca para o meio da relação professor-aluno. Em outras palavras, Tardif não aponta para polo algum da relação, mas, sim, para o seu processo, para a interação e os fundamentos interativos que sustentam a co-presença de professores e alunos em ensino-aprendizagem.

Em Tardif, as categorias tempo, trabalho e condições sociais direcionam ao olhar, mas entendemos que o sentido desse olhar só se completa quando ele amplia a ideia de trabalho docente como um trabalho sobre e com o ser humano. A humanidade do ato educativo resgata a subjetividade do professor que ganha voz e vez nas pesquisas em educação. O saber da experiência - elemento fundador de suas formulações - seria o saber profissional docente por excelência, pois representaria a mobilização do mosaico formado pelos demais saberes adquiridos na formação acadêmica e fora dela, ao longo de toda a história de vida de uma pessoa. A valorização da história individual e profissional do professor na perspectiva de Tardif parte de pressupostos anteriormente apontados por Shulman; contudo, ele avança no sentido de nos fornecer uma leitura mais crítica quanto à visão do professor como sujeito epistêmico, que se coloca em preparação e atuação profissional. Por exemplo, para Shulman (1996), a divisão, a organização e a apresentação da matéria aos alunos constituem meios pedagógicos com os quais os professores pretendem atingir seus objetivos. Nesse sentido, o conjunto dos meios utilizados pelos professores poderia ser designado como uma tecnologia do ensino. Na visão de Tardif, tentar racionalizar esse instrumental docente esbarra na própria natureza das tecnologias e dos saberes utilizados pelos professores: são tecnologias imbricadas na "problemática do poder no âmago das interações humanas" (2005, p. 262). As técnicas que os professores utilizam não se fundamentam nas ciências, mas, sim, em saberes cotidianos, formulados nas inter-relações sociais. As ciências da educação não dão respostas simples sobre o "como fazer" e, na maior parte do tempo, os professores tomam decisões e desenvolvem estratégias de ação sem fundamento tecnocientífico algum. É nesse cenário que Tardif introduz a ideia de que as tecnologias do ensino correspondem às tecnologias da interação, identificando três delas: a coerção, a autoridade e a persuasão (ibidem, p. 265).

Ao pensar no papel do professor, diante do aluno, de reunir todos os recursos que possui com a finalidade de promover uma ação que leve a um aprendizado, percebemos que essa "tecnologia" depende do professor, da pessoa que ele é, daquilo que pensa sobre o 
mundo, sobre a matéria que leciona, sobre o que pensa sobre eles próprios, os alunos. Depende do seu envolvimento como pessoa com a profissão que escolheu, mas não só isso. Também depende da consciência que tem da sua humanidade, o respeito e o afeto que tem por esta humanidade. As estratégias que usa para entrar em interação com os alunos são infrutíferas se não procura, com o seu trabalho, respeitá-los no crescimento, na identidade em formação. Dessa forma, nosso olhar se dirige para o horizonte proposto por Paulo Freire. E quando Paulo Freire escreve "é que o trabalho do professor é o trabalho do professor com os alunos e não do professor consigo mesmo" (1998, p. 71) percebemos, então, que nossos olhares se cruzaram ao de Tardif.

Entre os vários olhares que podemos lançar sobre a sala de aula, entre os descritos por autores consagrados na pesquisa e no campo da educação ou mesmo entre os olhares ainda não descritos, parece-nos incontestável aquele que permite ver, ou melhor, que compartilha a ideia de que os sujeitos envolvidos no processo educativo constroem-se mutuamente em uma espécie de laboratório de aprendizagens em que é possível evidenciar momentos de construção de identidades, ora singularizados, ora marcados socioculturalmente. O nosso olhar sobre o olhar dos parceiros teóricos aqui elencados permite perceber que nossas construções teóricas vão se amalgamando e com elas - como um caleidoscópio - vamos dando corpo às nossas práticas por meio dos discursos produzidos sobre essas práticas. Não conseguimos perceber facilmente o momento em que o nosso olhar cruzou/se uniu com o deles. Parece que estivemos juntos ou que pensamos parecido porque vivemos algo semelhante... É difícil precisar, mas a distância entre os nossos saberes e os saberes adquiridos com os parceiros teóricos parece se atenuar no exercício da escrita. As nossas possibilidades de pensar e os limites do nosso olhar colocam-se em exposição aqui. Somos parte do que lemos e refletimos de todos eles. E, ao escrever, nos recompomos, nos construímos e nos singularizamos. O exercício a que nos propomos é esse. E ao fazê-lo, queremos evidenciar a construção da nossa identidade profissional, marcada pelo que somos, pela nossa história, pelo nosso tempo/espaço e por todos os parceiros teóricos com os quais cruzamos olhares e ideias.

\section{O PROJETO UM CORPO EM CONSTRUÇÃO}

Nosso objetivo na pesquisa realizada como tese de doutorado, produzida pela primeira autora e sob orientação da segunda, foi o de evidenciar os saberes adquiridos e acumulados durante o percurso no projeto Um corpo em Construção, bem como o de capturar, por meio dos registros, as interações e os significados que engendraram a construção desses saberes.

A atividade pedagógica em questão foi realizada na disciplina de Ciências e é um recorte do referido projeto realizado pelos alunos do $8^{\circ}$ ano de uma instituição pública de ensino, do âmbito federal, no município do Rio de Janeiro, que prevê a construção de um corpo humano feito no interior de um molde de acetato e a da história dele como personagem em uma narrativa ficcional. Assim, não é só a localização de órgãos e componentes físicos do corpo que está em foco, mas, principalmente, a criação de uma história para o personagem, narrada pelos alunos que o construíram. 
Como colocar isso em prática? Contatamos um artesão que fazia uns bonecos em acetato para escolas de samba da cidade do Rio de Janeiro. Pronto! Estava resolvido. Encomendaríamos o molde, apenas a carcaça, e os alunos montariam o corpo humano por dentro aos poucos, conforme as unidades do programa fossem abordadas teoricamente em sala. E como se daria a elaboração do personagem? Inicialmente, pensamos em sugerir aos alunos que dessem "qualidades" aos sistemas do corpo à medida que eram construídos e montados. Pensávamos em explorar os temas relacionados ao órgão sadio ou não, enfim, aspectos ainda muito dependentes de uma visão organicista do corpo. Mas, não demorou muito, percebemos que não era só isso o que queríamos. Então, amadurecemos a ideia da produção de uma história para cada corpo, assim como nós temos. Cada corpo, uma história. Nasceu o projeto Um corpo em Construção.

Desde o início do trabalho, pudemos perceber pelas discussões que surgiam em sala de aula, que ocorria uma espécie de mergulho dentro do corpo, em uma tentativa de torná-lo palpável. Alguns alunos desenvolviam um relacionamento de cuidado e zelo extremo com seu boneco e se esmeravam na construção de órgãos e sistemas esteticamente muito bem feitos. Outros apresentavam tanta dificuldade que tornava difícil a conclusão do trabalho. A construção do corpo/molde possibilitava ao aluno uma aproximação e um confronto entre a sua representação de corpo e a representação oferecida pelo livro didático.

A abordagem das situações de vida narradas permite não só o acesso a um diálogo interno. Permite, também, a prática da reflexão de si e a captura/resgate da origem ou existência de certos saberes/conhecimentos que estão na base das nossas ações e orientações pedagógicas. Por esses registros também podemos compreender o nosso modo de fazer escolhas, de promover vínculos ou parcerias e de procurar os fios condutores que definem nossas intenções e objetivos pedagógicos.

Decidimos recorrer a fragmentos da memória e compor, com eles, uma narrativa em que a negociação entre os conhecimentos adquiridos e a experiência - que se enfrentam e dialogam - busca dar sentido à prática pedagógica. Uma narrativa analítica e interpretativa se constrói sob o fio da navalha. Exige implicar-se na ação e no discurso. Decisão delicada, porém, rica em possibilidades e que prevê a abertura a novas formas de pensar a formação docente, implicando a própria existencialidade na formação profissional.

Um dos aspectos mais apontados como diferencial do Projeto Um Corpo em Construção com relação às estratégias de ensino de Ciências é a possibilidade da construção da história do personagem. Ela traz a humanidade ao corpo humano, singulariza-o dentro de sua anatomia plural, definidora da espécie Homo sapiens. O que cabe a nós, em nossa singularidade pode ser expresso aqui, não para garantir que o nosso ponto de vista sobre a nossa prática seja aceito ou tomado como a verdade, mas, sobretudo, para pôr à disposição uma história que é, ao mesmo tempo, singular e plural; constituidora em sua essência dinâmica, contraditória e fragmentada das histórias de formação profissional desse tempo/espaço.

Neste artigo, trazemos um momento revivido pela memória com um dos grupos 
naquele ano letivo. Momento atualizado pela nossa narrativa sobre um dia de montagem dos órgãos do sistema reprodutor pelos alunos. Esse grupo de alunos-autores deu vida/corpo ao personagem Carlos Eduardo.

\section{A História de Carlos Eduardo ${ }^{3}$}

Essa é uma das histórias mais desafiadoras construídas no projeto Um Corpo em Construção. Desafiadora porque evidencia os limites das abordagens escolares e coloca em xeque nossas certezas científicas. A história de Carlos Eduardo traz uma narrativa ficcional atual, em uma linguagem objetiva e clara. Está situada geograficamente na cidade do Rio de Janeiro e fala de comportamentos e hábitos presentes no universo jovem da zona sul carioca.

É possível acompanhar o percurso de um grupo de alunos que, inicialmente desorganizados e desarticulados, se veem envolvidos em um processo de criação e autoria que os mobiliza e os faz criar estratégias de união e cooperação. Um grupo que escapou às regras e aos mecanismos que eu inventei para enquadrá-los e controlá-los, modificando e adaptando a proposta do projeto Um Corpo em Construção a seu próprio projeto, à sua criatividade.

\section{Primeiro momento: $O$ dia de montagem do grupo}

Acertar na composição do grupo de alunos não é tarefa simples. Como eles têm liberdade de escolha, inevitavelmente, acabam adotando como critério afinidades pessoais, amizades. Essa escolha, entretanto, nem sempre favorece a formação de um grupo de trabalho com habilidades complementares, com capacidade de negociação e organização. Esse grupo era um desses casos.

Era formado por cinco meninas e um único menino. Logo na primeira montagem, percebi que havia algo estranho no ar. Entraram no laboratório, cabisbaixos, quietos. Entreolhavam-se, mas nada diziam. Sentaram.

Aproximei-me deles e observei que tinham trazido apenas uma bexiga de borracha vermelha para aquela montagem. Estranhei aquele silêncio, justamente pelo fato de serem muito falantes durante as aulas teóricas, demonstrando haver muita afinidade em comum. Perguntei a eles o que estava acontecendo e acabei detonando uma "bomba nuclear". Todos começaram a falar ao mesmo tempo, acusando-se mutuamente. Sem entender muito bem o que diziam, pedi: líder.

- Prestem atenção! Um de cada vez! O que está acontecendo? Vamos começar pela

A líder era a Karina, a que mais recebia críticas. E Karina se defendeu:

\footnotetext{
${ }^{3}$ A partir de agora, o texto é narrado em primeira pessoa, pela Professora Mônica em seu trabalho na disciplina de Ciências, com os alunos.
} 
- Olha só, professora, essa coisa de líder não dá certo, não. Eu tenho inglês nas terças e quintas, a Júlia tem nas segundas e quartas e a Luana tem teatro e balé todos os dias... Ela nunca vai quando a gente marca. Assim fica difícil.

Todos se defendem e se acusam. Interferi:

- Deixa eu ver se estou entendendo. Vocês não se organizaram e por isso não fizeram nada. É isso?

Luana responde e pergunta com jeito de quem não quer saber a resposta...

- É professora. O que você vai fazer?

Estava dividida. Acreditava que o estabelecimento e o esclarecimento das regras no início do ano eram fundamentais para que o curso tivesse o andamento esperado e que tais regras deveriam ser iguais para todos. Também esperava que o planejamento do Projeto $U m$ Corpo em Construção se encaixasse no calendário das atividades trimestrais do colégio. Logo, o que eu poderia fazer? Sem estar convencida do que deveria fazer com aquele grupo, pedi a eles para pensar um pouco.

No interior do laboratório, há um compartimento que chamamos de paiol. No paiol, guardo antigos materiais que sobram durante as montagens, usados pelos alunos. Fui até lá e chamei o grupo. Mostrei os materiais guardados e perguntei:

- Será que vocês conseguem achar aqui alguma coisa interessante para modelar?

- Hum... Não sei. Será? - questionou Luana.

- Bom, o que posso fazer é isso. Se vocês forem bem criativos, podem modelar os órgãos ainda hoje. Mas quero chamar a atenção que isso é um improviso. Não espero isso de vocês...

Deixei que eles ficassem ali pensando, planejando como resolveriam a situação. A ideia era fornecer algum material para que o tempo da aula fosse aproveitado no sentido de permitir as aprendizagens referentes aos órgãos que seriam montados. Naquele momento, achei que estava fazendo a coisa certa perante eles e os outros alunos da turma. Tentei trazêlos à rotina do trabalho, enquadrá-los.

Tardif e Lessard nos falam sobre essa ação docente tão recorrente nas salas de aula, o enquadramento da situação escolar:

Para o professor, enquadrar é, dentro de um processo de interação com os alunos, determinar os limites, as significações e as orientações da situação que o grupo de alunos se prepara para viver. É colocar pontos nos "is", consignar tarefas, registrar funções, definir condutas, para gerar um quadro situacional que permitirá o trabalho escolar propriamente dito, ou seja, o processo de ensino e aprendizagem. Fundamentalmente, aqui o trabalho consiste em deslanchar uma ação coletiva, quer dizer, organizar, coordenar e orientar as condutas de vários indivíduos - os alunos na direção escolhida pelo professor. Devido a isso, portanto, o trabalho suscita obrigações e lógicas estratégicas de ação coletiva (CROZIER; FRIEDBERG, 1981, apud TARDIF; LESSARD, 2007, p. 177).

Depois de um curto intervalo de tempo, voltei ao paiol para ver o que estavam fazendo. Lembrei também que não haviam entregado a primeira parte da história do personagem nem a pesquisa sobre os órgãos.

- E aí? Já resolveram o problema de vocês? - Perguntei. 
Luana me respondeu:

- Não, professora. A gente tentou, mas não é isso que a gente quer fazer. A gente não quer improvisar só para ter nota.

- E o que vocês querem fazer?

- A gente pode montar fora do horário da aula? Em outro dia?

- Mas vocês não podem entrar no laboratório sem a presença da professora. A direção da escola não permite...

- E se você for na direção dizer que confia na gente e deixa a gente trabalhar aqui em outro horário?

Nesse momento, percebi que estavam em plena negociação. Entre eles e entre eles e eu. Resolvi apostar neles.

- Tudo bem. E se eu fizer o que estão propondo, até semana que vem a montagem estará pronta?

Luana se antecipa:

- Amanhã, professora! É o tempo que a gente precisa...

- Bem, então vamos lá na direção para tentar a permissão. Mas, e a história?

- Podemos te passar por e-mail?

- Ah, essa é boa!

- Claro, professora. É muito melhor. A gente conversa com tudo pelo $\mathrm{MSN}^{4}$, podemos conversar com você também. Pode ser?

- Hum... Tudo bem.

Naquele mesmo dia, à noite, recebi o e-mail de uma das meninas com a primeira parte da história de Carlos Eduardo. Achei muito interessante logo que li. Quando retornei à escola, observei que haviam montado os órgãos do sistema reprodutor como me prometeram e não houve problemas em relação à permanência deles no laboratório. Tudo transcorreu tranquilamente. Um dado novo: havíamos feito um pacto de confiança. Apostei no grupo e não me decepcionei. A partir daquela montagem - obviamente - voltaram a discutir, a resmungar, mas algo parecia chamar-lhes ao compromisso. Não queriam apenas a nota, o lugar-comum, o improviso. Queriam o lugar de autores e criadores, ainda que desorganizados e desarticulados. Conversávamos muito e aos poucos foram criando um esquema próprio para os encontros de planejamento do trabalho.

Como Tardif e Lessard (2007), defendo o contexto interativo cotidiano em que o trabalho docente opera. Esse tipo de trabalho a que me refiro é aquele que envolve "a existência de meandros recorrentes de conhecimentos, emoções, juízos de valores susceptíveis de ser constantemente reformulados nas relações entre o produtor e o usuário" (op. cit., p. 33). Nesse episódio, por exemplo, é no contexto da interação que emerge as questões de poder e até mesmo as de conflitos entre nossos propósitos.

${ }^{4}$ MSN é a sigla dada para o programa de conversação online, Windows Live Messenger. 
Não queria ser ludibriada por eles; queria que se envolvessem como os demais grupos, nos prazos determinados por mim. Entretanto, desse conflito surgiu um movimento, um novo olhar, uma outra possibilidade. Quando a estratégia proposta por eles se impôs à minha, um saber ali se instaurou: eles não eram como os outros, nem poderia reduzi-los à imagem que tinha deles, a qual queria conservar. Compreendi que se para alguns grupos a figura do líder é benéfica e ajuda na organização dos trabalhos, para outros, como no caso desse grupo, ela desajusta e desalinha a possibilidade do trabalho cooperativo. Quando escrevo sobre esse grupo, imediatamente entro em interlocução com as minhas lembranças de leitura de Michel de Certeau. Em seu livro A invenção do cotidiano: artes de fazer (1996), ele ressalta a importância de se investigar porque certos indivíduos e grupos, usando formas criativas de lidar com as imposições, não se submetem à disciplina. Inseridos em um mesmo sistema de regras, esses grupos se diferenciariam pelo uso que fazem de tais regras, distinguindo dois tipos de operações: as estratégias, relacionadas a movimentos dentro de uma previsibilidade e de um lugar pré-determinado; e as táticas, envolvendo subversão, manipulação desses lugares e criação de novos espaços (op. cit., p.100).

O jogo de negociações do qual participamos me leva a pensar nessa captura de novos lugares e na construção, com astúcia, de autonomia e poder. A "tática” engendrada pelo grupo possibilitou duas aquisições importantes para mim e para a execução do projeto $U m$ Corpo em Construção: 1) a partir daquele momento, todos os grupos puderam trabalhar, nos seus horários vagos, no interior do laboratório. Eles passavam na direção e pegavam a chave do laboratório, com toda a responsabilidade que um trabalho coletivo requer; e 2) passei a me comunicar com todos os alunos, de forma rápida e efetiva, pelo MSN ou por e-mail. Eles adoraram! 


\begin{abstract}
A tática não tem por lugar senão o do outro. E por isso deve jogar com o terreno que lhe é imposto tal como o organiza a lei de uma força estranha. Não tem meios para se manter em si mesma, à distância, numa posição recuada, de previsão e de convocação própria: a tática é movimento "dentro do campo de visão do inimigo"... Este não-lugar lhe permite sem dúvida mobilidade, mas numa docilidade aos azares do tempo, para captar no vôo as possibilidades oferecidas por um instante. Tem que utilizar, vigilante, as falhas que as conjunturas particulares vão abrindo na vigilância do poder proprietário. Aí vai caçar. Cria ali surpresas. Consegue estar onde ninguém espera. É astúcia (CERTEAU, op. cit., pp. 100/101).
\end{abstract}

O fato de trabalhar com grupos de alunos traz duas questões importantes: a da igualdade de tratamento e a da organização da atividade. Trabalhando com e para os alunos, devo atentar aos movimentos e demandas de cada grupo, sem perder de vista a relação ética que nos perpassa e sustenta como turma e professora. Cada grupo tem tanta importância quanto todos os outros, mas cada composição é única, pois cada aluno tem necessidades e expectativas diferentes, conferindo um perfil específico ao seu grupo de trabalho.

As interações que estabelecemos em sala visam a assimilação de conteúdos, mas também a aquisição de comportamentos designados como importantes para a execução da atividade pedagógica. Confrontar-me com esses dilemas, sobretudo face a face, tem possibilitado uma ampliação da minha capacidade de interação e de promoção de aprendizagens.

Vale a pena lembrar uma ideia proposta por Shulman em seu modelo de ação e raciocínio pedagógico, porém tomada a partir da perspectiva da interação. Refiro-me à ideia de reflexão desenvolvida por Shulman (2004): fase ou momento em que o professor olha para trás, reconstrói e recaptura emoções e eventos. Segundo esse autor, a reflexão deve confrontar os acontecimentos com os objetivos desejados. Mas, quando relembro o que aconteceu comigo e esse grupo no seu primeiro dia de montagem, percebo que tal reflexão - na proposta de Shulman - torna-se parcial se não levar em consideração a perspectiva do aluno e de interlocutores teóricos que subjazem à nossa prática. Neste episódio, a concepção de reflexividade como um elemento formador da minha profissionalidade se coaduna com as proposições de Sadalla e Sá-Chaves (2007). As autoras ressaltam que para que a reflexividade contribua para o fazer-pensar e o saber-fazer dos professores, é preciso levar em consideração os contextos históricos, políticos e sociais em que se configuram as práticas escolares.

\footnotetext{
Nesta perspectiva, destaca-se a necessidade da reflexão sobre a prática tendo como base a apropriação de teorias como elemento fundamental para a melhoria de práticas de ensino, em que o professor é ajudado a compreender o seu próprio pensamento e a refletir criticamente sobre sua prática, construindo e significando seu saber-fazer, entrelaçando a ele novos instrumentos de ação (SADALLA; SÁCHAVES, op. cit., p.34).
}

Posso dizer que as aquisições promovidas pelo grupo, como o de poder frequentar o laboratório em outros dias da semana além dos dias das aulas de Ciências e a ampliação dos meios de comunicação entre a professora e os alunos pela internet, foram aquisições mais amplas, pois caracterizaram uma ampliação do campo didático-docente abrangido pelo \begin{tabular}{l|l|l|l|l|l|l} 
(C) ETD - Educ. Temat. Digit. & Campinas, SP & v.18 & n.1 & p. 250-268 & jan./abr.2016 & ISSN 1676-2592
\end{tabular} 
projeto Um Corpo em Construção. Por meio da minha escuta, vi a possibilidade de criar e ocupar as fissuras produzidas com uma nova forma de pensar e agir. Essa escuta a que me refiro também se constitui em um saber: ao escutá-los, aprendi a lição de transformar o meu discurso - por tantas vezes tido como a fala aos alunos - em uma fala com os alunos. Tal reflexão só foi possível porque se deu no contexto interativo da ação educacional.

As situações vividas no projeto Um Corpo em Construção possibilitaram a integração e a mobilização de saberes que corroboraram com a ideia de Tardif et al. (1991) quando se referem ao saber docente como um saber plural. As relações estabelecidas com os alunos e todas as escolhas que perpassam a dinâmica execução do projeto refletem esse conjunto de conhecimentos/saberes intercomunicantes.

O professor padrão é alguém que deve conhecer sua matéria, sua disciplina e seu programa, que deve possuir certos conhecimentos das ciências da educação e da pedagogia, sem deixar de desenvolver um saber prático fundado em sua experiência cotidiana com os/as alunos/as. (p. 221)

A discussão que faço neste estudo vincula-se, especialmente, a um tipo de saber que Tardif (1991) chamou de saber da experiência. Saber da experiência é uma denominação desse autor para a diferenciação de saberes produzidos na formação acadêmica. São os saberes adquiridos na prática diária dos(as) professores(as). No entanto, devo defender que tal experiência e, portanto, tal saber, constituiu-se à medida que, buscando subsídios em diferentes referenciais teóricos tais como o da psicologia de Vygotsky, procurei interlocuções e articulações com a realidade que se apresentava, face a face, no cotidiano da minha sala de aula e nas produções dos alunos, como ponto de referência, constituindo, dessa forma, a minha identidade docente. Em outras palavras, segundo Loguercio e Del Pino (2003), "a produção do outro contribui para nossa autoprodução como ponto de relação e de comparação" (p. 20).

Neste meu processo de reflexão, as contribuições de Vygotsky para a compreensão dos processos interativos que se produzem em sala de aula sempre foram muito marcantes em minha formação acadêmica docente. No mestrado, quando investiguei acerca dos usos de intervenções orais dos alunos por uma professora em um contexto interativo, reafirmei a minha crença na linguagem como "inter-ação", decorrendo desse fato o seu uso como estratégia docente/discente para a (re)construção dos significados em uma aula de Ciências (Guimarães, 2000).

Com base nos pressupostos de Vygotsky, já afirmava que:

[...] a unidade básica de análise do processo de ensino e aprendizagem já não é a atividade individual do aluno e sim a atividade articulada e conjunta do aluno e do professor em torno da realização das tarefas escolares. A atividade do aluno que está na base do processo de construção do conhecimento está inscrita de fato no domínio da interação ou interatividade professor/aluno (GUIMARÃES, op. cit., p. 28).

Hoje, neste estudo, um novo encontro se deu com Vygotsky. Desse encontro, um novo pensar a respeito das relações que estabeleço com os meus alunos e com o meu fazer 
pedagógico, o meu trabalho. (Re)vejo o projeto Um Corpo em Construção e me dou conta das estratégias de interação que produzi por meio não somente da linguagem oral como instrumento imediato, mas também das múltiplas formas de linguagem geradoras de interação com os meus alunos, incluindo a própria atividade docente/discente.

Neste projeto quero defender a imprevisibilidade das estratégias de interação. Mesmo em atividades planejadas e executadas repetidas vezes, as estratégias de interação que se dão em sala de aula emergem no próprio contexto da situação ou atividade em que se encontram o professor e os alunos. O resultado da estratégia usada é sempre uma produção multirreferenciada, potencialmente geradora de novos saberes docentes. Portanto, a ideia de se atribuir ao processo interativo professor/aluno uma tecnologia me parece a negação da própria essência do princípio da interação, em que cada elemento da relação contribui, ao seu modo, à sua possibilidade naquele dado momento.

Observando algumas ações desencadeadas pelos alunos no cotidiano escolar e que, frequentemente são interpretadas como subversões ou rebeldia à ação do professor, muitas delas poderiam ser consideradas como apenas jogos de negociação de poder. Essa é a leitura que faço com relação ao caso do grupo do Carlos Eduardo, no seu primeiro dia de montagem. Não havia ali uma intenção por parte dos alunos em subverter a atividade; ao contrário, havia uma tentativa de adequação. Adequação entre os meus propósitos e os deles, o que conferiria poder de escolha e decisão para ambos os lados da relação. Em outras palavras, por causa das estratégias de interação utilizadas, compartilhamos decisões e construímos novas possibilidades de efetivação da tarefa a ser executada. E esse foi mais um grande saber!

Sendo assim, acredito que os atributos relativos à capacidade de negociação possam compor uma possibilidade de estratégia de interação. Nessa perspectiva, uma estratégia de interação, sobretudo no campo educacional, deve acolher a fala do outro, buscar um equilíbrio de forças, prever a aceitação do novo. São os próprios autores da expressão criticada anteriormente, Tardif e Lessard (2007), que reiteram a ideia de multirreferencialidade quando afirmam que o trabalho docente constrói e mobiliza saberes e habilidades que subjazem a várias modalidades de interação humana, incluindo as de caráter afetivo e ético. Incluir a negociação de poder como uma estratégia de interação no processo educativo é ampliar a possibilidade da aquisição de autonomia pelos alunos.

\section{Segundo momento - O dia da exposição de Carlos Eduardo}

No dia da preparação para a exposição, o grupo era um dos mais agitados. Ficamos alguns dias antes da exposição trabalhando sem parar. Eu observava o movimento deles, mas não imaginava o que estava por vir. Ainda não havia lido o texto final da história e parecia que a intenção era esta: causar-me surpresa.

Tiramos as fotos para a exposição final e como eles eram muito divertidos e até um pouco "teatrais", não cheguei a desconfiar das "caras e bocas" e dos trejeitos que faziam enquanto eu os fotografava. Quando cheguei para abrir o laboratório no dia da exposição, 
entendi o alvoroço daquele grupo quando olhei para o que estava arrumado. Eles haviam preparado o material para a exposição do Carlos Eduardo com todo o cuidado e detalhamento. Apresentando Carlos Eduardo estavam alguns trechos do tex to da história de seu personagem e também os guardanapos utilizados para escrever ao seu amado sua declaração de amor e a descoberta de sua homossexualidade. A escrita de tal carta conforme a história descreve - acontece em um quiosque à beira-mar, na praia de Ipanema, em frente à rua Vinícius de Morais, como o grupo relatou:

Carlos Eduardo é um rapaz bonito, forte, loiro, tem olhos claros, 24 anos de idade e está fazendo o curso de Educação Física na UFRJ. É simpático e bastante popular. Entretanto, nos últimos meses, tem andado muito preocupado, pois não está conseguindo obter um bom desempenho em suas relações sexuais, apresentando dificuldades na ereção e esse problema está afetando diretamente o relacionamento com as suas parceiras. Carlos, que era um rapaz descolado, bom de papo, agora andava nervoso e muitas coisas passavam pela cabeça. Ele chegou a pensar se era homossexual, mas ao lembrar de suas parceiras e o prazer que obtinha nas relações antes do problema, descartou essa possibilidade...

Carlos que sempre fora bom aluno, agora ia mal nos estudos, chegava atrasado nas aulas, de ressaca, não estava mais fazendo a sua parte na casa que alugara com os amigos de faculdade, e mal visitava seus pais. Antes, sempre que tinha tempo, ia lá lhes fazer visitas.

Carlos continuou nessa vida de farra por dois anos. Já estava dependente do álcool, e os sintomas da cirrose começaram a aparecer. Seu peso tinha diminuído, sentia dores abdominais, seu sono começou a ser alterado, estava fraco, cansado e o que é pior, essa receita de relaxar não lhe cabia mais, pois a cirrose fez com que sua impotência aumentasse e seu interesse sexual diminuísse.

Sentido saudade do caçula, seus pais foram procurá-lo para conversar, ele não atendia mais o telefone, nem dava sinal de vida. Quando ligavam pra casa dele, os amigos diziam que ele havia saído, e isso pra eles estava passando dos limites. Então foram procurar-lhe no período que ele tinha livre, entre a faculdade e as festas...

Já um pouco melhor da cirrose, Carlos Eduardo foi passar um final de semana na casa de campo de seus pais, em Itaipava. Era aniversário de 36 anos de sua tia Maria Clara. Foram jogar futebol. Mas Carlos começou a passar mal, sentia-se tonto, sem ar: era a asma atacando novamente.

Começou a soltar um fraco grito de desespero pedindo por socorro, mas foi em vão, e em poucos segundos, Carlos estava caído no chão, desmaiado. O jogo foi interrompido na hora. Ele, socorrido com um pouco de água da piscina no rosto, acordou. Logo sua mãe, desesperada, foi buscar sua bombinha que havia deixado em seu carro. A bombinha que lhe acompanhava por quase toda a sua vida, pois ele tem asma desde os 6 anos de idade. Na bolsa havia um remédio anti-inflamatório, pois a causa da falta de ar seria uma inflamação nos brônquios e o remédio agiria de imediato, possibilitando a entrada de ar nos pulmões...

Ele estava muito confuso e decidiu fazer o que Daniel havia lhe ensinado: escrever seus sentimentos para sentir-se um pouco aliviado e poder então tomar decisões com calma. Dirigiu-se para um quiosque à beira-mar e pegou alguns guardanapos, já que não estava 
com seu caderno, pediu um refrigerante e a caneta do garçom por alguns minutos. Começou a escrever como estava se sentindo com relação a Daniel, desde que o conheceu até a noite de ontem.

E com o mais verdadeiro sentimento, começou a escrever o que sentia:

"Sempre senti algo inexplicável por ele, porém achava que era um sentimento de paciente com psicólogo, uma relação de confiança, uma grande amizade. Quando estou com ele sinto-me livre, aliviado, bem, acreditando que posso confiar em alguém. Tenho um carinho imenso por ele, Daniel é uma pessoa especial, diferente, talvez mais que um amigo simplesmente. Aceitei o convite para a boate na noite passada, pois estava vivendo ótimos momentos de companheirismo com ele, achei que não seria nada demais, abrir um pouco a mente para novas coisas, começar a aceitar melhor as pessoas como elas são e se divertir um pouco não seria nada mal depois de um longo dia. Só que eu não esperava que a diversão fosse tão intensa e acabasse se estendendo por toda à noite. Não esperava descobrir ali a razão pela qual não estava tendo um desempenho sexual muito bom com minhas parceiras. Não esperava descobrir ali do que realmente gostava, não esperava descobrir ali, meu real sentimento por Daniel. Não estava preparado. Mas aconteceu. Nós dois estávamos ali, sentados, conversando, vendo todos se divertirem e o clima foi se tornando mais propício a isso enfim nos beijamos. E por incrivel que pareça, me senti bem, muito bem. Melhor do que todas as vezes que tinha beijado alguém. Porque ali, realmente tinha um sentimento, algo guardado dentro do peito, forte, que pulsava loucamente. Então, o clima foi esquentando e o desejo aumentando e enfim nos dirigimos para um motel, onde passei a noite mais prazerosa de minha vida, ao lado da pessoa que descobri que realmente amava."

Carlos releu o texto escrito e pensando duas vezes, ligou para Daniel, afinal, não seria certo escrever aquelas singelas palavras enquanto seu amado estava em um quarto de um motel sozinho...

\section{CONSIDERAÇÕES FINAIS}

A narrativa do texto dos alunos sobre Carlos Eduardo nos leva a questionar a composição e a organização fossilizada dos conteúdos escolares pertinentes à disciplina de Ciências. Por exemplo, questões como a homossexualidade, a bissexualidade, o aborto, o uso abusivo de remédios, entre outros, ainda são evitadas no interior do sistema escolar. Os conhecimentos que a Biologia e a Genética podem fornecer jamais darão a um professor o caminho que ele precisa percorrer para abordar tais temas - tão controversos, mas necessários - em sala de aula. Dessa maneira, a base do conhecimento científico sobre o qual o professor se apoia se vê fragilizada. Além disso, a pesquisa em educação fornece pouca resposta precisa ou diretamente utilizável pelo professor.

Quando lemos e relemos o texto de Carlos Eduardo, refletimos sobre a nossa impossibilidade de capturar, pelas formas usuais de ensinar, a maneira como eles entendem alguns dos dilemas humanos. A descoberta da homossexualidade de Carlos Eduardo a partir de um relacionamento afetivo, calcado em confiança e amizade sugere um olhar sobre o corpo humano como algo para além do seu aspecto meramente físico. $\mathrm{O}$ trabalho apresentado 
concretamente pelo grupo - o corpo montado - traz o estudo biológico de um corpo masculino, porém a trama construída pelo grupo foi além das expectativas. Trabalhando com a complexidade do ser humano, a história de Carlos Eduardo fala sobre as indeterminações humanas, mas também de algumas certezas: o nosso corpo biológico carrega um outro corpo, psicológico e social; e constituímo-nos na presença do outro, ou seja, buscamos e precisamos do outro para nos conhecer. Estando inscrita em um contexto social familiar ao grupo - são moradores da zona sul do Rio de Janeiro -, a narrativa traz uma realidade não vivida, mas talvez observada por eles ou mesmo relatada a partir de pessoas de convivência próxima e que aparece ali ressignificada como objeto de estudo.

A abordagem delicada e cuidadosa a respeito da homossexualidade de Carlos Eduardo revela uma dimensão ética da aprendizagem efetuada pelo grupo no projeto do Corpo, pela demonstração de respeito ao outro e pela ousadia em abordar - sem juízo de valores - um tema que ainda é objeto de preconceito sexual na sociedade e na escola.

Com a história de Carlos Eduardo vemos ampliada a possibilidade de o professor exercer uma mediação entre os conhecimentos científicos escolares, os conhecimentos prévios dos alunos e as profundas transformações sociais e culturais em curso na nossa sociedade. A relação conhecimento-escola transformada pela demanda desse grupo se configurou em um meio capaz de promover novos debates e novas aprendizagens não somente para esses alunos-autores, mas também para toda a turma e para todos os que visitavam a exposição, durante a qual Carlos Eduardo foi um destaque e só se ouviam elogios à sua história por parte dos visitantes.

Com o olhar entrelaçado às contribuições de Shulman e Tardif, queremos indicar alguns pontos que tomamos como não conclusivos, mas que sintetizam lições que emergiram deste estudo e que nos provocaram novas inquietações:

- Para além da questão das fontes e dos modos de construção dos saberes docentes, identificamos, na interação professor/aluno, uma base fundamental para a construção de saberes docentes em consonância com as demandas psicológicas e sociais dos alunos, sendo o contexto interativo um mediador na articulação e integração do conhecimento do conteúdo da disciplina com o conhecimento pedagógico deste conteúdo.

- Se compararmos o saber específico de outras profissões, podemos observar que as dimensões reflexiva, analítica e contextual não nos bastam como caracterizadoras. A dimensão negociadora de poder que o professor pode - e deve - adquirir se torna imprescindível se pretendemos uma educação voltada para a promoção de autonomia pelos alunos.

- Se o saber docente é heterogêneo, se emerge de diferentes fontes, se é compósito e surge quando integrado e mobilizado na atividade docente, nos parece razoável que o saber discente também possa ser tomado sob essa perspectiva. Dessa forma, entendemos como privilegiadas as condições pedagógicas que favorecem a construção de saberes discentes sob esse prisma, ou seja, o da pluralidade, do inacabamento e da mobilização de tais saberes. 
Esse é o desafio da dimensão interativa da docência: nenhuma dimensão - cognitiva, instrumental, procedimental, afetiva ou experiencial - se esgota em si mesma. Na docência, o professor precisa estar em interação, precisa do outro da relação, seja aluno, outro professor, agente escolar, psicólogo escolar, os pais dos alunos, enfim, de todos os que compõem a sua comunidade educativa. A proposta de um trabalho interdisciplinar, envolvendo efetivamente a participação de outras disciplinas como o Português, a História, as Artes Plásticas, a Música, entre outras, abriria um novo leque de possibilidades para a dinâmica dos saberes escolares ainda tão fragmentados e pouco articulados. Novos olhares e novos saberes poderiam recuperar outras formas de dialogar com as múltiplas realidades que se apresentam face a face conosco nas salas de aula. Saberes que as ciências ainda não conhecem.

Recorremos à Clarice Lispector (1998, p. 12) para finalizar este artigo:

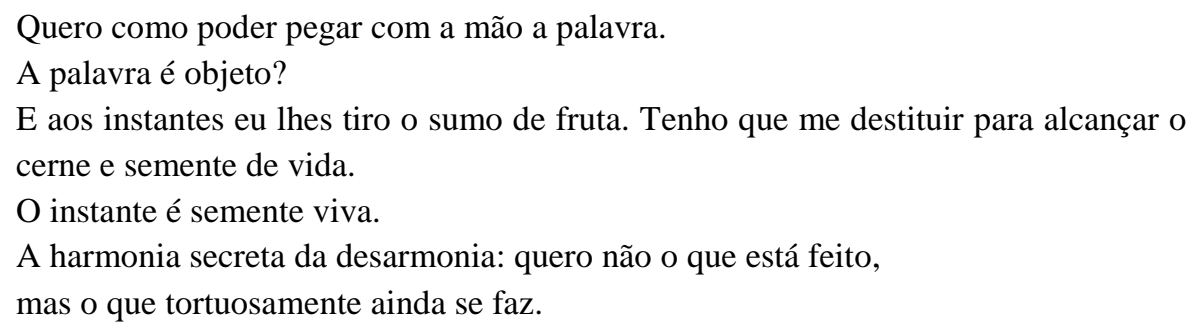

É isto: queremos sempre o que se está tortuosamente sendo feito. Aquilo que passa entre as brechas. Aquilo que não nos foi dado como coisa certa e pronta, mas se apresenta como a única possibilidade naquele instante. Por isso, nós precisamos de cada instante. Cada instante com o aluno é único porque somos únicos e estamos inteiros no que fazemos. 


\section{REFERÊNCIAS}

CERTEAU, Michel de. A invenção do cotidiano: artes de fazer. Tradução de Ephraim Ferreira Alves. Petrópolis: Vozes. 1996.

CUNHA, Maria Isabel da. O professor universitário na transição de paradigmas. Araraquara: JM, 1998.

FREIRE, Paulo. Pedagogia da autonomia: saberes necessários à prática educativa. São Paulo: Paz e Terra, 1998.

GAUTHIER, Clemont; MARTINEAU, Stephane; DESBIENS, Jean-François; LIMA, Francisco Pereira de; MALO, Annie. Por uma teoria da pedagogia: pesquisas contemporâneas sobre o saber docente. Ijuí: Editora Unijuí, 1998.

GUIMARÃES, Mônica Narciso. A educação em Ciências em um contexto interacional: o uso das intervenções orais dos alunos. 2000. Dissertação (Mestrado em Educação) Faculdade de Educação, Universidade Federal Fluminense, Niterói, RJ, 2000.

JOSSO, Marie-Christine. As histórias de vida como territórios simbólicos nos quais se exploram e se descobrem formas e sentidos múltiplos de uma existencialidade evolutiva singular-plural. In: PASSEGGI, Maria Conceição (Org.). Tendências da pesquisa (auto) biográfica. Natal: EdUFRN: São Paulo: Paulus, 2008. p. 23-50.

LISPECTOR, Clarice. Água viva. Rio de Janeiro: Rocco, 1998.

LOGUERCIO, Rochele de Quadros; DEL PINO, José Carlos. Os discursos produtores da identidade docente. Ciência \& Educação, Bauru, SP, v. 9, n. 1, p. 17-26. 2003. Disponível em: <http://goo.gl/3POy4n>. Acesso em: 02 jul. 2015. ISSN 1980-850X.

PRADO, Guilherme do Val Toledo; CUNHA, Renata Barrichelo (Org.). Percursos de autoria: exercícios de pesquisa. Campinas: Alínea, 2007.

SADALLA, Ana Maria Falcão de Aragão; SÁ-CHAVES, Idália da Silva Carvalho.

Constituição da reflexividade docente: indícios de desenvolvimento profissional coletivo.

Relatório de estágio pós-doutoral. Portugal: Universidade de Aveiro, 2007.

SADALLA, Ana Maria Falcão de Aragão, SÁ-CHAVES, Idália da Silva Carvalho. Constituição da reflexividade docente: indícios de desenvolvimento profissional coletivo. ETD - Educação Temática Digital, Campinas, SP, v. 9, n. 2, p. 189-203. jun./2008. Disponível em: < http://goo.gl/13kgG0>. Acesso em: 02 jul. 2015. ISSN 1676-2592.

SHULMAN, Lee. Paradigms and researcher programs in the study of teaching: a contemporary perspective. In: WITTROCK, Matthew. (Org.) Handbook of research on teaching. 3. ed. New York: MacMillan, 1986a.

SHULMAN, Lee. Those who understand: knowledge growth in teaching. Educational Researcher, Washington, v. 15, n. 2, 1986b. 
SHULMAN, Lee. Knowledge and teaching: foundations of the new reform. Harvard Educational Review. Harvard, v. 57, n. 1. February 1987.

SHULMAN, Lee. The wisdom of practice: essays on teaching and learning to teach. San Francisco: Jossey-Bass, 2004.

TARDIF, Maurice. Saberes docentes e formação profissional. Petrópolis: Vozes, 2002.

TARDIF, Maurice; LESSARD, Claude. O trabalho docente: elementos para uma teoria da docência como profissão de interações humanas. Tradução de João Batista Kreuch. 3. ed. Petrópolis: Vozes, 2007.

TARDIF, Maurice; LESSARD, Claude. O trabalho docente: elementos para uma teoria da docência como profissão de interações humanas. Tradução de João Batista Kreuch. 3. ed. Petrópolis: Vozes, 2007.

TARDIF, Maurice; LESSARD, Claude. O ofício de professor: histórias, perspectivas e desafios internacionais. Tradução de Lucy Magalhães. Petrópolis: Vozes. 2008.

TARDIF, Maurice; LESSARD, Claude; LAHAYE, Louis. Os professores face ao saber: esboço de uma problemática do saber docente. Teoria e Educação, Porto Alegre, RS, n. 4, p. 215-233. 1991.

TARDIF, Maurice; RAYMOND, Danielle. Saberes, tempo e aprendizagem do trabalho no magistério. Educação \& Sociedade, Campinas, SP, v. 21, n. 73, p. 209-244. dez./2000. Disponível em: 〈 http://goo.gl/i2d1L〉. Acesso em: 02 jul. 2015. ISSN 1678-4626.

\section{Como citar este documento:}

GUIMARÃES, Mônica Narciso; ARAGÃO, Ana Maria Falcão de. A construção de saberes em um processo de ensino e de aprendizagem de ciências: uma história para contar. ETD - Educação Temática Digital, Campinas, SP, v. 18, n. 1, p. 250-268, abr. 2016. ISSN 1676-2592. Disponível em: <http://periodicos.sbu.unicamp.br/ojs/index.php/etd/article/view/8637514>. Acesso em: 05 abr. 2016. doi: 〈http://dx.doi.org/10.20396/etd.v18i1.8637514>. 